\title{
FIELD RUN-UP MEASUREMENTS: CALIBRATION OF A PHYSICALLY BASED LAGRANGIAN SHORELINE MODEL
}

\author{
Carlo Lo Re ${ }^{1}$, Giorgio Manno', Antonino Viviano², Enrico Foti ${ }^{2}$
}

\begin{abstract}
In the present contribution a measurement technique based on video imaging has been selected for the assessment of the maximum run-up. Such measurements have been used for the calibration of a numerical model and of an empirical formulation. The on-site run-up measurements have been carried out at "Lido Signorino" beach, near Marsala, Italy. The positions of the swash have been localized on a transect, normal to the shore, constituted by stakes placed at $0.5 \mathrm{~m}$ intervals each other. The video camera was placed orthogonally to the line of the stakes. For the numerical simulations a 1DH Boussinesq-type of model for breaking waves has been applied which takes into account the wave run-up by a Lagrangian shoreline model. In such simulations monochromatic waves have been propagated in a numerical flume having the same beach slope of the measured transect. The comparison between registered and estimated run-up have underlined an acceptable agreement. In particular, it has been obtained that the numerical model tends to underestimate the run-up, instead the applied empirical formula gives overestimated values.
\end{abstract}

Keywords: wave run-up; field measurements; shoreline modeling

\section{INTRODUCTION}

The oscillations of the shoreline are produced by interaction between waves and beach with a consequent absorption and/or reflection of wave energy. The wave motion has a fundamental role in studying the most important coastal phenomena. Indeed the waves feel the morphology of the bottom when moving closer to the shore, so changing direction and shape and dissipating energy. Of particular importance is the breaking phenomenon, that occurs when the crest celerity exceeds the wave velocity; as a result the wave falls down forming a breaker, that uses its kinetic energy to run-up in the so called swash zone with presence of turbulence. After that, the wave runs down resulting in backwash.

This persistent motion allows the shoreline to change continuously, moving back and forward not only depending on beach morphology but also because of sea level variation depending on wave, tide and currents. Therefore the coastline represents a fluctuating boundary, whose localization it is a very difficult and uncertain task. Despite of this intrinsic characteristic, the shoreline is the most peculiar element of the coastal area. Its localization is fundamental in order to design and plan coastal defense structures and in order to manage and monitor all the human activities falling in this area.

A very popular method for locating the shoreline consists in using aerial images. Such a method on the one hand fixes the "objective" situation of boundary between beach and sea surface at the moment of shoot, on the other hand doesn't give information on the state of sea surface in that moment (breaking, run-up, run-down, etc.), so causing uncertainties on the real meaning of the line of separation showed by the aerial image (Manno et al., 2011). Therefore it is important to consider the wave run-up on beach estimating. In such a framework, the main object of the present contribution is the comparison between field run-up measurements in the beach of Lido Signorino (near Marsala, Italy; see Figure 1) and the run-up assessments by means of both an empirical formula proposed by Nielsen and Hanslow (1991) and a Boussinesq type of model (Lo Re et al., 2012). The studied beach, as the Figure 1 shows, is located in the west part of Sicily, it is sandy and morphologically stable. Moreover the wave buoy offshore Mazara del Vallo is located at less than $30 \mathrm{~km}$ from there. For such a reason, the presented work started from wave data acquisition that were geographically transposed and, from there, the waves were propagated up to the studied site. After the adopted methods of run-up assessment were explained, their application to the chosen case study was performed; finally a comparison with field data was executed.

\section{PRELIMINARY HYDRAULIC STUDY}

It is known that the run-up on a beach of given morphology is determined mainly by wave and tide level. In the present paper, our attention was only focused on wave motion, neglecting tide effects. In order to find the effects of wave motion on the position of shoreline in the studied beach, it was necessary to identify the offshore wave parameters (significant wave height and period). For such a

\footnotetext{
${ }^{1}$ Department of civil, environmental, aerospace, materials engineering, University of Palermo, viale delle scienze, bldg. 8, Palermo, 90039, ITALY

${ }^{2}$ Department of civil and environmental engineering, University of Catania, viale Doria 6, Catania, 95125, ITALY
} 
reason, the data recorded by the Mazara del Vallo buoy were employed in the same hours in which the run-up measurements in the Lido Signorino Beach were performed. In order to analyze the data, it was necessary to identify the geographic fetch, i.e. the maximum length of water over which a given wind may blow, and the effective fetch by taking into account the well known expression derived by the theory of indirect wave modeling (Saville 1962, Seymour 1977).
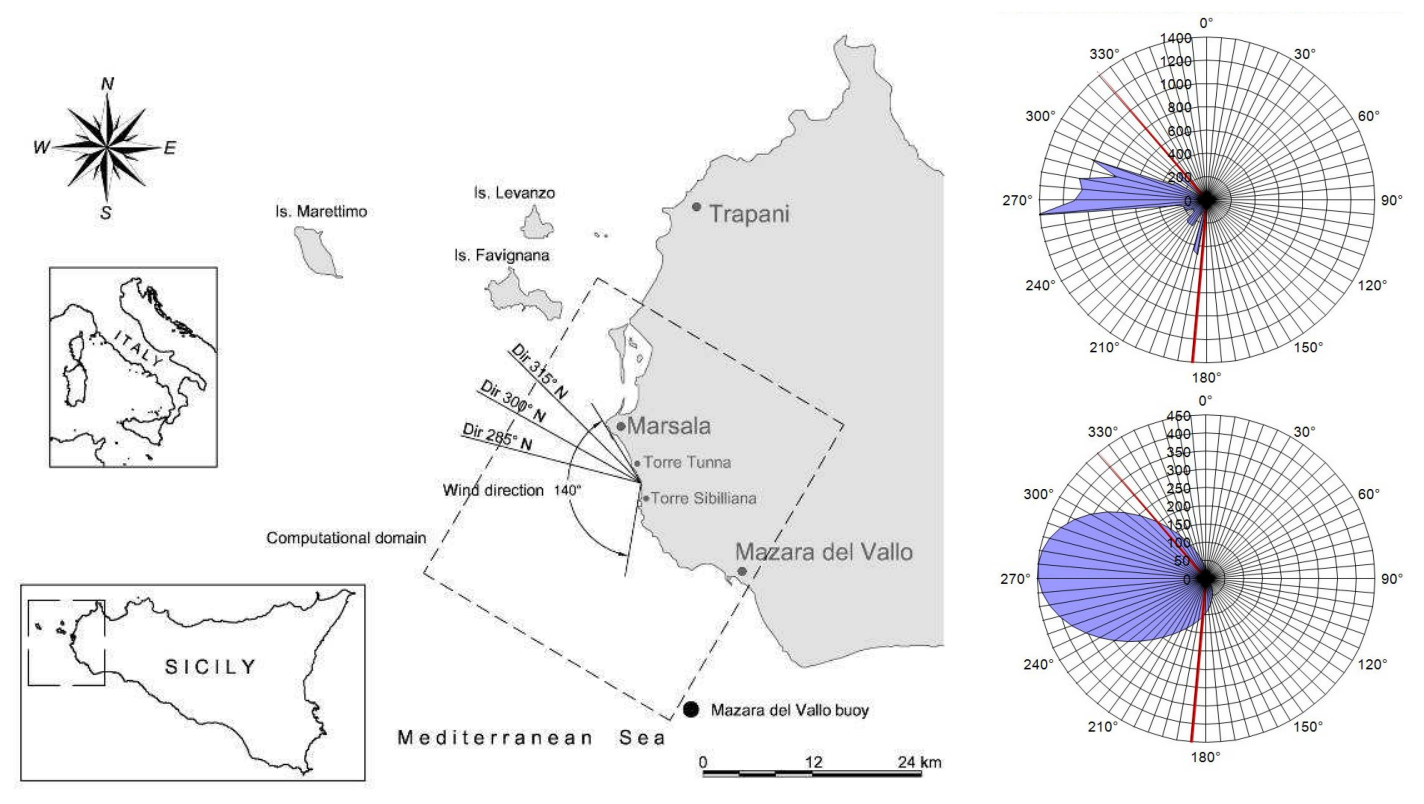

Figure 1. Geographic position of the Lido Signorino beach. The computational domain of the study area is showed in dashed line; wind and principal wave directions together with buoy position are also showed.

The recorded wave parameters, even though are representative of the climatic exposition of the studied coast, doesn't take into account of the different geographic position between the buoy and the Lido Signorino beach. For this reason, it was applied a geographic transposition in order to move the wave parameters from the buoy to a point located offshore of the beach. Since the beach has a limited fetch, the equations used in order to calculate the significant wave height $\left(H_{s}\right)$ and the peak period $\left(T_{p}\right)$ in function of the fetch length are (Vincent, 1984):

$$
\frac{H_{s}^{P}}{H_{s}^{O}}=\left(\frac{F^{P}}{F^{O}}\right)^{1 / 2} ; \quad \frac{T_{p}^{P}}{T_{p}^{O}}=\left(\frac{F^{P}}{F^{O}}\right)^{1 / 3}
$$

in which $F$ it is the effective fetch of the considered direction, the superscript $O$ and $P$ state, respectively, for the measured and the transposed point. Evidently the use of these expressions implied that the wind velocity should be the same in the two point, that is very probable looking at the relative position of buoy and beach.

After the wave parameters were calculated with the above mentioned formula the SWAN (Simulating Waves Nearshore) spectral model (Booij et al. 1999, Holtuijsen et al. 1993, Ris et al. 1999) was used in order to calculate the significant wave height and the peak period of inshore wave, as reported in Manno (2012).

\section{WAVE RUN-UP ASSESSMENT}

The inshore waves, calculated by means of SWAN, were used in order to estimate the wave run-up, i.e. the maximum vertical extent of wave uprush on a beach above the still water level (SWL). Two approaches were followed for the evaluation of this parameter: i) the empirical formula proposed by Nielsen and Hanslow (1991); ii) the numerical model developed by Lo Re et al. (2012). Both methods were used by considering the beach profile (Manno, 2012) located in the center of the Lido Signorino coast, having a mean slope of $7 \%$. 


\section{The empirical formulation}

As it is well known, several empirical formulae are available to calculate the wave run-up (Holman and Sallenger, 1985, Raubenheimer and Guza, 1996, Hughes, 2004). In the present paper the Nielsen and Hanslow (1991) formula was used. Such authors carried out measurements in six beach of the New South Wales (Australia). The offshore wave parameters are collected from a buoy located $30 \mathrm{~km}$ from shore. The Beaches were made by fine sands, with a mean diameter between $0.4 \mathrm{~mm}$ and $0.22 \mathrm{~mm}$, with geomorphologic characteristics similar to those of Lido Signorino. In particular, Nielsen and Hanslow (1991) verified that the run-up heights are well represented by a Rayleigh distribution:

$$
F(R)=1-\exp \left\{-\frac{\left(R-R_{100}\right)^{2}}{L_{z w m}^{2}}\right\}
$$

in which $R_{100}$ is the value transgressed by $100 \%$ of the waves, i.e. the lower limit of the distribution, and $L_{z w m}$ is the vertical scale of the distribution, i.e. the shape parameter.

The authors found a strong correlation of $R_{100}$ with $\left(H_{0 r m s} \cdot L_{0}\right)^{0.5}$, of $L_{z w m}$ with $\left(H_{0 r m s} \cdot L_{0}\right)^{0.5}$ and $\tan \gamma$ as follow:

$$
\begin{gathered}
R_{100}=\beta \cdot\left(H_{0 r m s} \cdot L_{0}\right)^{0.5} \\
L_{z w m}=\alpha \cdot\left(H_{0 r m s} \cdot L_{0}\right)^{0.5} \tan \gamma
\end{gathered}
$$

where $H_{0 r m s}=0.706 \cdot H_{s}$ is the root mean square of offshore wave, $L_{0}=g T^{2} /(2 \pi)$ is the corresponding wave length, $\tan \gamma$ is the slope of the beach, $\alpha$ and $\beta$ are coefficients.

For the Australian beaches they proposed the following expressions:

$$
\begin{gathered}
L_{z w m}= \begin{cases}0.60 \cdot\left(H_{0 r m s} \cdot L_{0}\right)^{0.5} \tan \gamma & \tan \gamma \geq 0,10 \\
0.05 \cdot\left(H_{0 r m s} \cdot L_{0}\right)^{0.5} & \tan \gamma<0,10\end{cases} \\
R_{100}=0.06 \cdot\left(H_{0 r m s} L_{0}\right)^{0.5}
\end{gathered}
$$

\section{The numerical model}

The calculus method for run-up applied by (Lo Re et al., 2012) used a Boussinesq type of model for breaking waves with the governing equations solved in the $\zeta-u$ form, where $\zeta$ is the free surface elevation and $u$ is the depth-averaged horizontal velocity. The values of variables $\zeta$ e $u$ were calculated inside the wet domain, whereas the shoreline position (defined by means of its horizontal coordinate $\xi(t)$ perpendicular to the coast) and its velocity $u_{s}$ were calculated by means of the Lagrangian shoreline equations. Indeed it is widely acknowledged that numerical simulation of shoreline oscillation with a Boussinesq type of model is a difficult task, because such kind of models cannot discriminate well between the wet and dry region. In the case of a mono-dimensional wave as that we considered, the variable $\xi$ is only function of time, i.e. $\xi=\xi(t)$ and the kinematic condition gives the following formula:

$$
\frac{d \xi}{d t}=u_{s}
$$

Such a relation states that the fluid particles at the shoreline remain along the shoreline (Prasad and Svendsen 2001). Moreover the momentum equation at the shoreline must be also considered in order to close the problem; in dimensional form such a shoreline equation reads:

$$
\frac{d u_{s}}{d t}=-\left.g \frac{\partial \zeta}{\partial x}\right|_{s}+F_{f r i c}
$$

where $\partial \zeta /\left.\partial \mathrm{x}\right|_{\mathrm{s}}$ is the derivative of the surface elevation evaluated at the shoreline, $F_{\text {fric }}$ is the bottom friction force evaluates as follow:

$$
F_{\text {fric }}=-\frac{f}{h+\zeta} \cdot u \cdot|u|
$$


in which $h$ is the local depth, $f$ is the bottom friction coefficient. When the value of $F_{f r i c}$ becomes too large, due to the small value of the total water depth, a threshold is used. In such a case, the dependency on the water depth has been eliminated and the bottom friction is assumed to be only a quadratic function of the depth-averaged velocity:

$$
F_{\text {fric }}=-C_{f} \cdot u \cdot|u|
$$

where $C_{f}$ is a coefficient that was assumed equal to $5.0 \mathrm{~m}^{-1}$ in the present work, such a value is based on the work of Lo Re et al. (2012).

\section{FIELD MEASUREMENTS}

The run-up on beaches may be measured in different ways depending on the general aim and on the amount of details required. Records of the water line positions can in principle be obtained by resistance run-up meters or by video-cameras as applied by Holman and Sallenger (1985). The technique applied in the present study is based on a high frequency monitoring video system.

Such kind of technique allows the acquisition of several images by means of a digital video camera and it seems to be very precious for the run-up measurements. The choice of the position of the camera was a fundamental task because the camera has to shoot the whole studied area but at a little distance, in order to obtain the maximum level of detail from the recorded images.

In particular, positions of the swash were measured on a transect across the beach, normal to the shore. For such a transect a line was built using stakes at $0.5 \mathrm{~m}$ intervals (Figure 2). The first stake was a piezometer and it was next to the beach step. The second stake of the line was placed at a distance of $5 \mathrm{~m}$ from the piezometer. The line stakes on the beach profile was georeferenced using control points from a topographic survey (Manno, 2012).
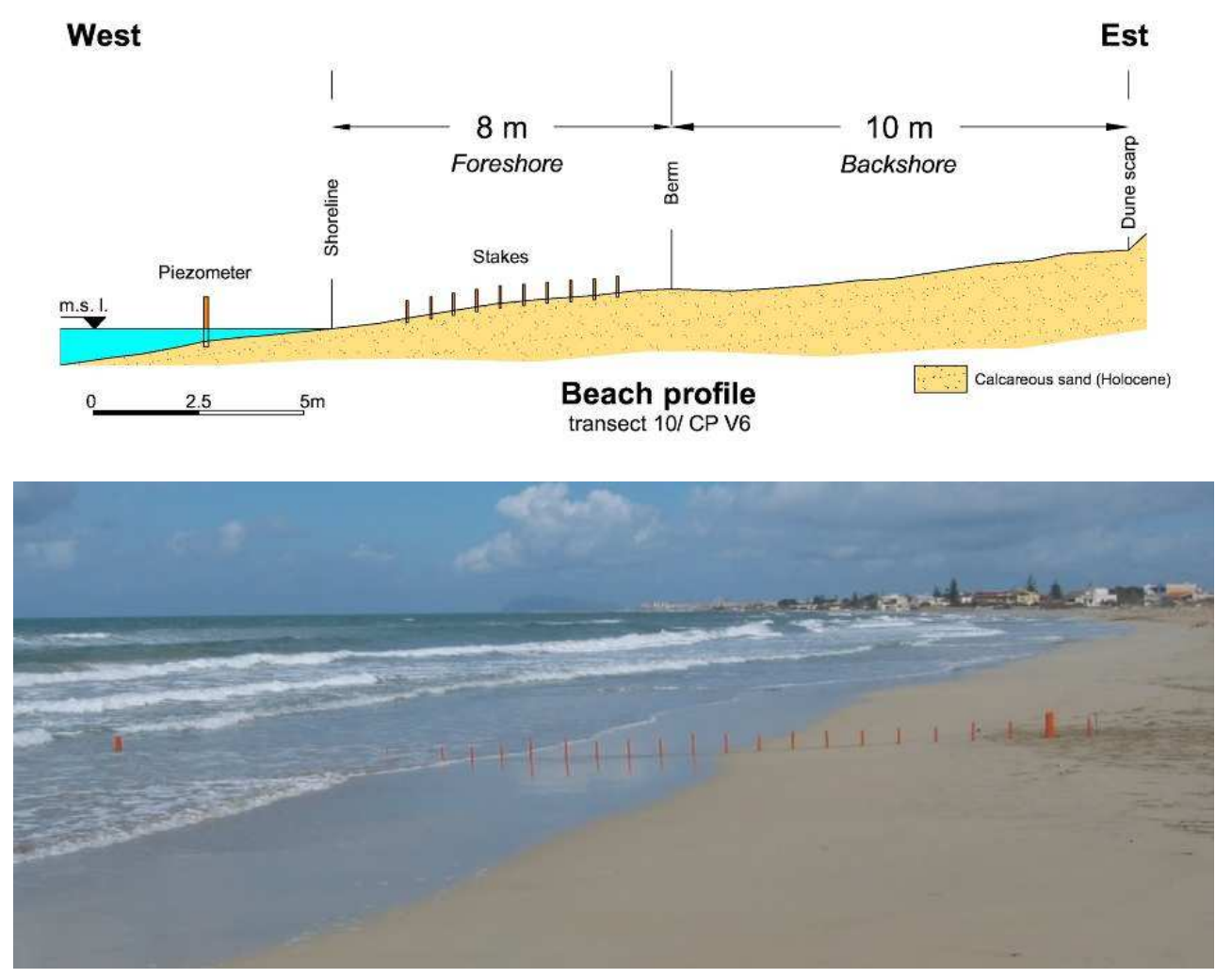

Figure 2. Cross section (high) and photograph (low) of the reference transect for the run-up measurements at Lido Signorino.

The video camera was placed at a distance of $10 \mathrm{~m}$ from the line of stakes (orthogonally), and it was used to record 240 minutes in continuous. The shot videos were digitized in order to extract the wave run-up of each wave. When a wave reached a stake the data was recorded. The horizontal run-up 
distance were calculated starting from SWL obtained from water level inside the piezometer. Finally the corresponding run-up value was estimated by considering the beach profile.

Each run-up measurement $(R)$ was recorded in time windows of thirty minutes (eight windows in total) accordingly to Nielsen and Hanslow (1991). For all the registered data, the Rayleigh distribution expressed by eq.(2) was fitted by using the method of least squares. The application of the Rayleigh distribution to our data allowed to estimate the $1 \%, 2 \%$, and $50 \%$ run-up, together with the significant run up, i.e. the run-up of the higher third.

\section{THE CASE STUDY}

The studied littoral, that got its name from one of the historical lido of the site, i.e. Lido Signorino, falls in the territory of Marsala in the South-West coast of Sicily, Italy. Such a coast has a gentle slope beach $\left(1.5^{\circ}<\tan \gamma<10.8^{\circ}\right)$ that stretches about $3.5 \mathrm{~km}$ in N-S direction ant it is located between two forelands. Moreover a highly variable wave climate is present which enables the collection of data over a wide range of incident wave condition. The westerly wind exposure, almost perpendicular to the beach, allows bidimensional effects to be neglected thus a 1DH model can be adopted. The soil texture of the beach is constituted by $0.4 \%$ of silt, $0.6 \%$ of clay and $99 \%$ of sand. The diameter of sand particles ranges between 0.18 and $0.8 \mathrm{~mm}$.

The anemology characteristics of the site were deduced by the analysis of wind velocities and directions recorded by the station of Trapani during the period between 2004 and 2008. The wind sector is $140^{\circ}$ wide and it is delimited in the north side by the headland of Torre Tunna $\left(325^{\circ} \mathrm{N}\right)$ whereas in the south such a sector is delimited by the headland of Torre Sibilliana $\left(185^{\circ} \mathrm{N}\right)$ (Manno, 2012). It is worth to point out that the Egadi archipelago, and in particular the Favignana Island, shades the beach along the direction $320^{\circ} \mathrm{N}$. The fetch is calculated by means of a map in $1: 2^{\prime} 250^{\prime} 000$ scale, measuring the distance coast to coast with a radial discretization of $5^{\circ}$. The fetch calculated in this way is limited in the west directions by Spain coasts, in the North-west directions by Sardinia Island and in the south directions by Africa.

In order to perform the run-up assessments, by following the above mentioned procedure, wave parameters from buoy of Mazara del Vallo (DATAWELL Directional wavec MkI) were adopted. In particular, the used parameters were: i) significant wave heights, $H_{\mathrm{s}}[\mathrm{m}]$; ii) peak and mean wave periods, respectively $T_{p}[\mathrm{~s}]$ and $T_{m}$ [s]; iii) mean wave direction $D_{m}\left[{ }^{\circ} \mathrm{N}\right]$. The extraction time period goes from 11:30 to 15:30 of 29 march 2011.

As before mentioned, the reciprocal position of buoy and beach (Figure 1) made it necessary to geographic transpose the wave parameters by means of eq. (1). The wave propagation was performed by means of the SWAN spectral model, using a specific rectangular calculus domain, with sides of 36.4 and $30.5 \mathrm{~km}$ adopting a square grid with side of $100 \mathrm{~m}$; the bathymetry was derived by nautical maps. The SWAN model furnished as output the wave parameters at $60 \mathrm{~m}$ and $5 \mathrm{~m}$ depth. All the considered wave parameters, both offshore and inshore, were reported in Table 1 in the correspondence of the measurement period.

\begin{tabular}{|c|c|c|c|c|c|c|c|}
\hline \multirow[t]{2}{*}{ Time period } & \multicolumn{2}{|c|}{ Deep water } & \multicolumn{2}{|c|}{-60 m depth } & \multicolumn{3}{|c|}{-5 m depth } \\
\hline & $\begin{array}{l}H_{s} \\
{[\mathrm{~m}]}\end{array}$ & $\begin{array}{c}T_{p} \\
{[s]}\end{array}$ & $\begin{array}{l}H_{s} \\
{[\mathrm{~m}]}\end{array}$ & $\begin{array}{l}T_{m} \\
{[\mathrm{~s}]}\end{array}$ & $\begin{array}{l}H_{s} \\
{[\mathrm{~m}]}\end{array}$ & $\begin{array}{c}T_{m} \\
{[s]}\end{array}$ & $\begin{array}{l}T_{P} \\
{[\mathrm{~s}]}\end{array}$ \\
\hline $11.30-12: 00$ & 1.13 & 6.13 & 1.12 & 5.04 & 0.86 & 4.81 & 6.16 \\
\hline $12.00-12: 30$ & 1.05 & 7.27 & 1.05 & 6.01 & 0.90 & 5.86 & 7.51 \\
\hline $12.30-13: 00$ & 1.07 & 5.94 & 1.05 & 4.90 & 0.89 & 4.76 & 6.10 \\
\hline $13.00-13: 30$ & 1.04 & 7.18 & 1.04 & 5.91 & 0.86 & 5.70 & 7.30 \\
\hline $13.30-14: 00$ & 1.03 & 7.25 & 1.03 & 5.99 & 0.87 & 5.83 & 7.47 \\
\hline $14.00-14: 30$ & 1.10 & 7.26 & 1.10 & 5.97 & 0.94 & 5.81 & 7.50 \\
\hline $14.30-15: 00$ & 0.99 & 6.93 & 0.98 & 5.69 & 0.82 & 5.48 & 7.03 \\
\hline $15.00-15: 30$ & 1.05 & 6.33 & 1.05 & 5.21 & 0.89 & 5.06 & 6.49 \\
\hline
\end{tabular}

The inshore wave parameters were used in order to estimate the run-up in the considered profile (Figure 2), by applying the Boussinesq type of model of Lo Re et al. (2012). Therefore a monochromatic wave train was adopted, with wave height equal to significant wave height and period equal to the peak period at $5 \mathrm{~m}$ water depth, with the numeric wave generator at $300 \mathrm{~m}$ from beach. This domain was discretized by using $\Delta x=1 \mathrm{~m}$ and $\Delta t=T / 300 \mathrm{~s}$. Moreover the propagation of 
different waves has been simulated for each of the 8 time window in which was divided the period of measurements. The Courant number ranged between 0.099 and 0.1522 . The obtained wave run-up are reported in Table 2. Such a table also shows, for each time window, the results obtained with the empirical formula by Nielsen and Hanslow (1991). The significant run-up determined by means of the Rayleigh distribution of field measurements is also shown.

\begin{tabular}{|c|c|c|c|c|}
\hline Time & $\begin{array}{c}\text { Numerical } \\
\text { model } \\
{[\mathrm{m}]}\end{array}$ & $\begin{array}{c}\text { Empirical } \\
\text { formula } \\
{[\mathrm{m}]}\end{array}$ & $\begin{array}{c}\text { Field } \\
\text { measurements } \\
{[\mathrm{m}]}\end{array}$ & $\begin{array}{c}\text { Calibrated } \\
\text { empirical formula } \\
{[\mathrm{m}]}\end{array}$ \\
\hline & $\mathbf{R}_{\mathrm{S}}$ & $R_{S}$ & $\mathbf{R}_{\mathbf{S}}$ & $\mathbf{R}_{\mathrm{S}}$ \\
\hline $11.30-12: 00$ & 0,52 & 0,75 & 0,73 & 0,67 \\
\hline $12.00-12: 30$ & 0,75 & 0,77 & 0,76 & 0,73 \\
\hline $12.30-13: 00$ & 0,57 & 0,73 & 0,72 & 0,69 \\
\hline $13.00-13: 30$ & 0,62 & 0,80 & 0,71 & 0,77 \\
\hline $13.30-14: 00$ & 0,71 & 0,84 & 0,75 & 0,78 \\
\hline $14.00-14: 30$ & 0,73 & 0,82 & 0,75 & 0,79 \\
\hline $14.30-15: 00$ & 0,61 & 0,77 & 0,76 & 0,76 \\
\hline $15.00-15: 30$ & 0,58 & 0,83 & 0,77 & 0,77 \\
\hline
\end{tabular}

The analysis of the significant run-up $\left(R_{s}\right)$ highlights that both methods gives acceptable results. In particular, the numerical model tends to underestimate the run-up, whereas the empirical formula tends to overestimate it. However the empirical formula gives overall result closer to the measurements. Probably, the less efficiency of the numerical model is due to the fact that it is best suited to simulate the propagation of long waves. Such a question will be analyzed in depth in future studies by using random wave and groups wave as input for the model.

Since it has been verified that the empirical formula of Nielsen and Hanslow (1991) gives results that seem to match in fairly good way with the field data, but tends to overestimate the run-up, a calibration of the coefficients $\alpha$ e $\beta$ has been performed for the beach of Lido Signorino, as follow:

$$
\tilde{\alpha}=\sum_{i=1}^{8} \frac{L_{z w m, i}}{\left(H_{0 r m s, i} L_{0, i}\right)^{0,5}} ; \tilde{\beta}=\sum_{i=1}^{8} \frac{R_{100, i}}{\left(H_{0 r m s, i} L_{0, i}\right)^{0,5}}
$$

These values are used to calculate the Rayleigh distribution parameters from which, for a given exceedance probability, it was possible to estimate the run-up as follow:

$$
R\left(P_{s}\right)=L_{z w m} \sqrt{-\ln \left(P_{s}\right)}+R_{100}
$$

The so obtained values of $R_{s}$ were showed in the forth column of Table 2. The comparison between these values and the corresponding field measurements shows that the calibration gave a good improvement to the run-up assessment, with estimated values close to the experimental ones.

The Table 3 summarize, for each time window of half an hour, the Rayleigh distribution parameters of Lido Signorino.

\begin{tabular}{|c|cccc|cc|}
\hline \multicolumn{7}{|l|}{ Table 3. Significant run-up and calibration coefficients $\boldsymbol{\alpha}$ and $\boldsymbol{\beta}$ for Lido Signorino beach. } \\
\hline \multicolumn{7}{|c}{ Calibrated empirical formula } \\
[im]
\end{tabular}

From the data presented in such a table it is possible to calculate the following mean values of the calibration coefficients: 


$$
\tilde{\beta}=0,062 ; \tilde{\alpha}=0,044
$$

Finally the Table 4 compares for each time window the 1\%, 2\%, 50\% and significant run-up for the in situ measurements and for the calibrated empirical formula. The percentages of error, reported in the forth column, are generally within the $10 \%$, so confirming that the empirical formula of Nielsen e Hanslow (1991), with the calibrated parameters on the basis of measurements, is suitable to estimate the wave run-up on the beach of Lido Signorino.

\begin{tabular}{|c|c|c|c|c|c|c|c|c|c|c|c|c|}
\hline \multirow[t]{2}{*}{ Time } & \multicolumn{4}{|c|}{$\begin{array}{c}\text { Field measurements } \\
{[\mathrm{m}]}\end{array}$} & \multicolumn{4}{|c|}{$\begin{array}{c}\text { Calibrated empirical } \\
\text { formula } \\
{[\mathrm{m}]}\end{array}$} & \multicolumn{4}{|c|}{$\begin{array}{c}\text { Percentage error } \\
{[\%]}\end{array}$} \\
\hline & $\begin{array}{l}\mathbf{R}_{1} \\
\%\end{array}$ & $\begin{array}{l}\mathbf{R}_{\mathbf{2}} \\
\%\end{array}$ & $\begin{array}{l}\mathbf{R}_{50} \\
\%\end{array}$ & & & $\begin{array}{l}\mathbf{R}_{\mathbf{2}} \\
\%\end{array}$ & $\begin{array}{l}\mathbf{R}_{50} \\
\%\end{array}$ & & $\begin{array}{c}\mathbf{R}_{1} \\
\%\end{array}$ & $\mathbf{R}_{\mathbf{2}} \%$ & $\begin{array}{c}\mathbf{R}_{50} \\
\%\end{array}$ & $\mathbf{R}_{\mathbf{s}}$ \\
\hline $11.30-12: 00$ & 0,94 & 0,89 & 0,56 & 0,73 & 0,87 & 0,83 & 0,55 & 0,67 & $\begin{array}{c}10 \\
-7,4\end{array}$ & $-7,0$ & $\begin{array}{l}10 \\
-1,9\end{array}$ & $-8,7$ \\
\hline $12.00-12: 30$ & 0,99 & 0,93 & 0,58 & 0,76 & 1,01 & 0,96 & 0,64 & 0,73 & 2,5 & 3,0 & 9,1 & $-4,0$ \\
\hline $12.30-13: 00$ & 0,90 & 0,86 & 0,57 & 0,72 & 0,83 & 0,79 & 0,52 & 0,69 & $-8,8$ & $-8,8$ & $-9,1$ & $-4,0$ \\
\hline $13.00-13: 30$ & 0,88 & 0,84 & 0,57 & 0,71 & 0,99 & 0,94 & 0,62 & 0,77 & 11,8 & 11,5 & 8,7 & 8,3 \\
\hline $13.30-14: 00$ & 0,93 & 0,89 & 0,60 & 0,75 & 1,00 & 0,95 & 0,63 & 0,78 & 6,7 & 6,6 & 5,3 & 4,5 \\
\hline $14.00-14: 30$ & 0,93 & 0,89 & 0,60 & 0,75 & 1,03 & 0,98 & 0,65 & 0,79 & 10,2 & 10,1 & 8,8 & 6,3 \\
\hline $14.30-15: 00$ & 0,95 & 0,91 & 0,61 & 0,76 & 0,93 & 0,88 & 0,58 & 0,76 & $-2,4$ & $-2,5$ & $-3,6$ & $-0,2$ \\
\hline $15.00-15: 30$ & 0,95 & 0,91 & 0,63 & 0,77 & 0,87 & 0,83 & 0,55 & 0,77 & $-7,8$ & $-8,2$ & $-12,0$ & 0,1 \\
\hline
\end{tabular}

\section{CONCLUSIONS}

The run-up assessment in sandy beaches was considered, using as case study a beach on the south west coast of Sicily (Italy), where a measurements campaign was performed. On the basis of wave parameters records in a near buoy, it was simulated the inshore wave climate using the SWAN model. The obtained wave parameters were used in order to simulate the run-up both by means of a Boussinesq type of model and a well known empirical formula.

The comparison between the simulated significant run-up values and the measured data showed that both the methods gives acceptable results and that the numerical model tends to underestimate the runup whereas the empirical formula tends to overestimate it. Nevertheless the empirical formulation gave the best overall assessments. The calibration of the empirical formula, executed by using the field measurements, allowed to improve the assessments provided from such a formulation. In particular, the errors were generally les then $10 \%$.

From this study appears that the Boussinesq type of models not always are suitable to correctly evaluate the run-up over natural mild slope beach, even if they are very sophisticated. The cause of such a mismatch can be recognized in the shortening of wave length whereas the local depth tends to zero.

On the other hand the empirical formula succeeded in estimating the run-up, especially after a calibration performed by means of in situ measurements. Future developments will regard the run-up assessment not using, in shallower water, wave simulated from records of offshore parameters, but using wave measured at intermediate water, just near the beach, so eliminating the inevitable approximation introduced by waves transposition from buoy location to a point offshore of the studied site and during their shoreward propagation.

\section{ACKNOWLEDGMENTS}

This work was financially supported by the Italian Research Program PRIN 2008 titled: "Operative instruments for the estimate of coastal vulnerability in the presence of sandy beaches also in the presence of coastal structures" (contract no. 2008YNPNT9_002).

\section{REFERENCES}

Archetti, R., and Romagnoli, C. 2011. Analysis of the effects of different storm events on shoreline dynamics of an artificially embayed beach. Earth Surface Processes and Landforms, 36,1449-1463.

Booij, N., Ris, R.C. and Holthuijsen, L.H. 1999. A third generation wave model for coastal regions, part I: model description and validation, Journal of Geophysical Research, 104, 7649-7666.

Holman, R.A., Sallenger, A.H., Jr. 1985. Setup and swash on a natural beach, Journal Geophysics Research, 90(C1), 945-953. 
Holthuijsen, L.H., Booij, N. and Ris, R.C. 1993. A spectral wave model for coastal zone. Proceedings of the $2^{\text {nd }}$ International Symposium on Ocean Wave Measurement and Analysis. New Orleans.

Hughes, S.A. 2004. Estimation of wave run-up on smooth, impermeable slopes using the wave momentum flux parameter, Coastal Engineering, 51(11-12), 1085-1104.

Lo Re, C., Musumeci, R.E. and Foti, E. 2012. A shoreline boundary condition for a highly nonlinear Boussinesq model for breaking waves, Coastal Engineering, 60, 41-52.

Manno, G. 2012. Localizzazione della linea di riva, in spiagge sabbiose stabili, considerando le fluttuazioni da onde e maree. PhD thesis, University of Palermo. (Italian).

Manno, G., Lo Re, C., Ciraolo, G. 2011. Shoreline detection in gentle slope Mediterranean beach. Proceedings of the 5th SCACR: International Short Conference on Applied Coastal Research.

Nielsen, P. and Hanslow, D.J. 1991. Wave run-up distributions on natural beaches. Journal of Coastal Research, 7, 1139-1152.

Prasad, R.S. and Svendsen, A. 2001. The boundary condition at the moving shoreline for nearshore models. Center for applied coastal research, Ocean Engineering Laboratory University of Delaware, Newark, 19716.

Raubenheimer, B., and Guza, R.T. 1996. Observations and predictions of run-up, Journal Geophysics Research, 101(C10), 25575-25587.

Ris, R.C., Booij, N. and Holthuijsen, L.H. 1999. A third generation wave model for coastal regions, part II: verification. Journal of Geophysical Research. 104(4), 7649-7666.

Saville, T. 1962. Freeboard allowances for waves in inland reservoirs. Journal of the Waterways and Harbours Division, 18, 92-124.

Seymour, R..J. 1977. Estimating wave generation on restricted fetches. Journal of the Waterway Port Coastal and Ocean Division, 103(2), 251-264.

Vincent, C.L. 1984. Shore Protection Manual, fourth edition, Washington. 